\title{
TERRA BRASILIS, TERRA AUSTRALIS - PARTE 04: COMPARAÇÃO ENTRE INFRAESTRUTURAS E SERVIÇOS DE TRANSPORTES EM CIDADES MÉDIAS CENTRAIS
}

\author{
Bruno Borges Mamede ${ }^{1}$
}

Lucas Devides Moreno²

Juliano Ximenes Pamplona Ponte ${ }^{3}$

\section{RESUMO}

Este artigo faz parte de uma série de estudos sobre as proximidades estruturais e sistemáticas entre Brasil e Austrália. Em especial nesta edição, serão analisadas e comparadas a presença e disponibilidade de infraestruturas e serviços de transporte de passageiros em cidades médias centrais de ambos os países. Considera-se aqui, como na totalidade da pesquisa, que ambos os países possuem mais semelhanças do que discrepâncias em diversos aspectos da administração de seus territórios nacionais e, nesta passagem, os aspectos de infraestrutura e disponibilidade de serviços de transporte urbana são o ponto-chave de parametrização e análise.

Palavras-Chave: Engenharia de Transportes, Geografia de Transportes, Engenharia Urbana.

\section{BRASILIS TERRA AUSTRALIS LAND - PART 04: COMPARISON OF INFRASTRUCTURE AND TRANSPORT SERVICES IN MEDIUM CITIES CENTRAL}

\begin{abstract}
This article is a part of a studies' series about the structural and systematical proximities between Brazil and Australia. Particularly in this issue, there will be analyzed and compared the presence and availability of infrastructure and services related to passengers' transportation in central medium cities in both countries. It is regarded in here, as in the whole research, that these two countries have more resemblances than discrepancies in many aspects of their national territories administration

\footnotetext{
${ }^{1}$ Comunicador Social (PUC-Rio) e Geógrafo (UERJ), Aluno de Mestrado em PEU/POLI/UFRJ e de Especialização em IPPUR/UFRJ, bruno.mamede@poli.ufr.br.

Engenheiro Civil (Mackenzie-SP), Aluno de Mestrado em PEU/POLI/UFRJ, lucas.moreno@poli.ufrj.br.

${ }^{3}$ Doutor em Planejamento Urbano e Regional (UFRJ), Professor em FAU/UFPA, jximenes@ufpa.br.
} 


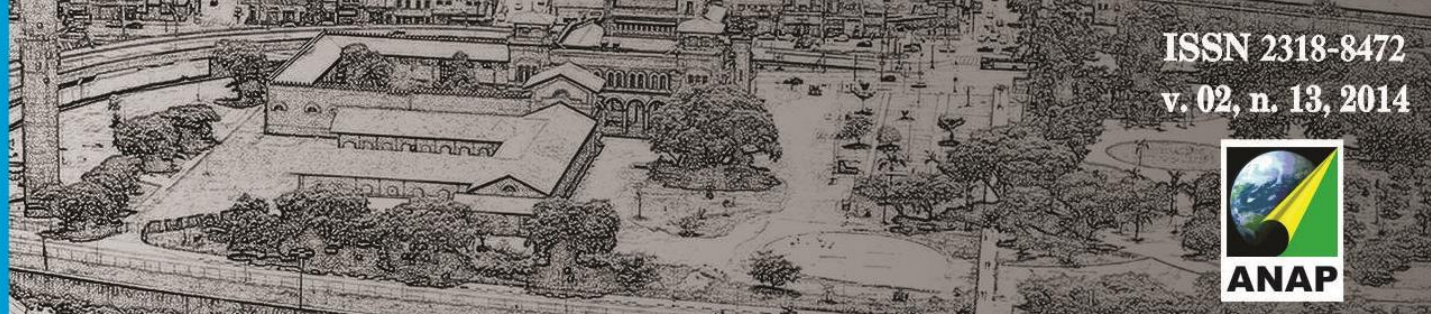

Revista Nacional de

Gerenciamento de Cidades

and, in this written, the aspects of infrastructure and availability of passengers' transportation services are the key points of parameterization and assay.

Keywords: Transportation Engineering, Transportation Geography, Urban Engineering.

\title{
BRASILIS TERRA AUSTRALIS TIERRA - PARTE 04: COMPARACIÓN DE INFRAESTRUCTURAS Y TRANSPORTE SERVICIOS EN MEDIO CIUDADES CENTRAL
}

\begin{abstract}
RESUMÉN
Este artículo hace parte de una serie de estudios acerca de las proximidades estructurales y sistemáticas entre Brasil y Australia. Especialmente en esta edición serán analizadas y comparadasla presencia y disponibilidad de infraestructura y servicios referentes a transportación de pasajeros en ciudades medianas de los dos países. Se ha considerado acá, como a toda la pesquisa, que estos dos países presentan mucho más semblanzas que discrepancias en muchos aspectos de la administración de sus territorios nacionales $y$, en este trabajo, los aspectos de infraestructura y disponibilidad de servicios para transporte de pasajeros son los puntos-llave de parametrización y análisis.
\end{abstract}

Palabras-clave: Geografía Urbana, Inguinaria Urbana, Administración Pública.

\section{INTRODUÇÃO DA QUARTA PARTE: PROPOSTA E OBJETIVO}

Conforme mencionado, este trabalho propõe-se a realizar um breve levantamento de experiências sobre o planejamento e a gestão de sistemas de transportes em cidades médias brasileiras e australianas. Acredita-se que em muitos aspectos ambos os países estão bem próximos e o intercâmbio entre suas experiências poderia gerar estudos muito ricos e práticas palpáveis para cada um.

A coletânea de estudos Terra Brasilis, Terra Australis dedica-se a demonstrar que os dois países possuem mais elementos em comum do que contraditórios, bem como estes elementos estarem muito mais nítidos do que fatos triviais como o tamanho de cada país e características geográficas gerais. Para além destes fatores, esta série pretende apresentar muitos dos aspectos em 



\section{Revista Nacional de}

Gerenciamento de Cidades

áreas Urbana e Transportes). Complementarmente, também serão utilizados dados recentes de ambos os países fornecidos por seus institutos nacionais de estatísticas e planejamento. Desta maneira, o método para a composição deste artigo está na análise e respectivo cruzamento de informações teóricas e dados estatísticos recentes para alcançar o referido objetivo desta publicação. Dentre os municípios aqui trabalhados, considera-se que o critério demográfico utilizados aos institutos estatísticos será aplicado a população de cada município, desconsiderando sua inserção em aglomerados urbanos (tanto como núcleo como periferida), salvo raras exceções que serão mencionadas quando necessárias.

Desta maneira, com o intuito de analisar os mecanismos, métodos e modelos de crescimento e expansão das redes de transporte das cidades médias australianas e brasileiras, este artigo compõe mais uma etapa da série de estudos dos autores em demonstrar que estes dois países possuem elementos que os tornam cada vez mais próximos em suas relações apesar da grande distância geografia e cultural presente.

No tocante ao objeto de estudos, o foco são as cidades de porte médio de acordo com critérios demográficos para cada instituto nacional. No caso brasileiro serão utilizadas cidades com população entre 100 mil e 750 mil habitantes, enquanto no caso australiano, as cidades em questão são aquelas com população entre 35 mil e 300 mil residentes, neste caso considerando aglomerados urbanos 4 . Os Mapas 01 e 02 - Divisão por estados de Brasil e Austrália apresenta as divisões em unidades federadas (estados e territórios) adotadas por cada país, com destaques para algumas das principais cidades (independentes de seus respectivos tamanhos e classificação na hierarquia urbana nacional.

\section{Mapas 01 e 02: Divisão por estados de Brasil e Austrália}

\footnotetext{
${ }^{4}$ Encontram-se algumas áreas inseridas na primeira categoria urbana da Estrutura de Estados (SOS: Structure of States) nível 0 (Outras Áreas Urbanas), onde estão populações entre 0 e 100.000 habitantes.
} 


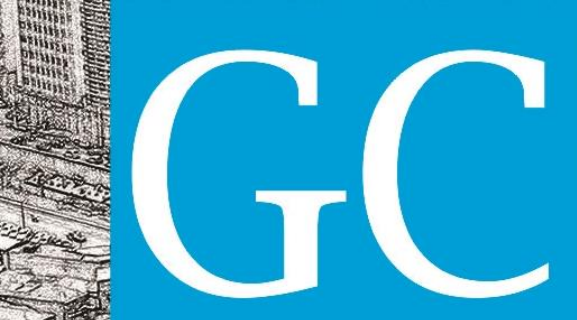

ISSN 2318-8472

Revista Nacional de

Gerenciamento de Cidades
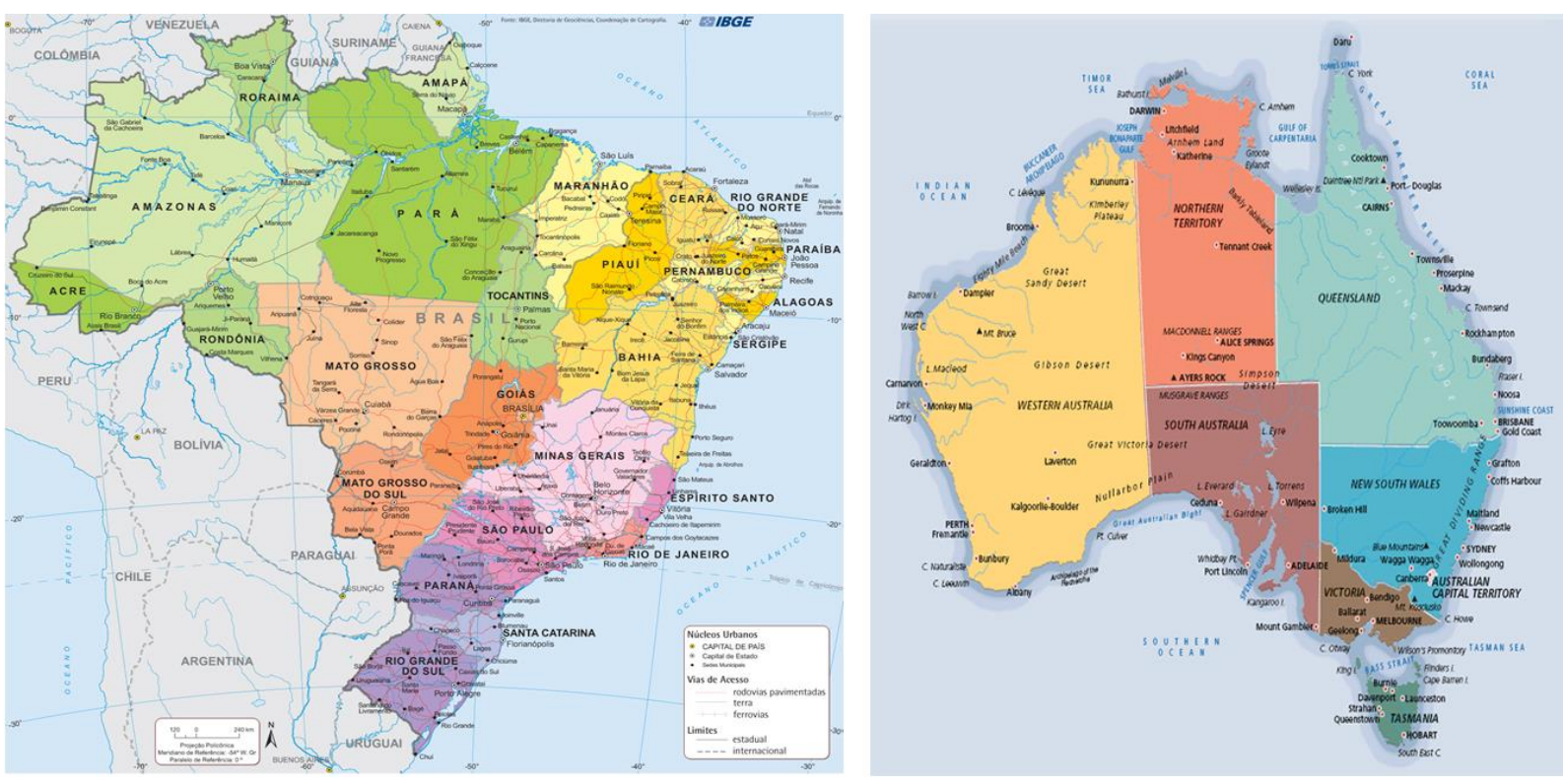

Fontes: IBGE (2010) e ABS

Adota-se este critério pois para os estados observados, as cidades nesta faixa populacional já concentram funções de comunicação com outras maiores regionais e estaduais, oferta de serviços especialidades não presente em grande parte das vizinhas e, acima disto, a maioria já está em aglomerados urbanos exercendo controle não somente regional, mas também por porções maiores do território (IBGE, 2010). A grande disparidade entre a população dos países deve ser considerada neste critério e devidamente relativizada. Após esta faixa populacional adotada encontram-se apenas 09 aglomerados urbanos já considerados metropolitanos ou Áreas Estatísticas de Grandes Cidades Capitais (GCCSA: Greater Capital Cities Statistical Areas) (ABS, 2012).

Ressalta-se que como a população total da Austrália representa $12,5 \%$ de toda população brasileira, então alguns números que, aparentemente, são discrepantes em valores absolutos serão utilizados proporcionalmente. Entretanto, o uso exato destas categorias poderia, ainda assim causar distorções às análises, em ambos os países e, desta forma, opta-se aqui em classificar como cidades médias brasileiras aquelas situadas entre 100.000 e 750.000 residentes no município e as australianas com população entre 30.000 e 300.000 residentes na unidade municipal (inclusas e somadas as subdivisões adotadas por cada estado). 

Revista Nacional de

Gerenciamento de Cidades

Brasil

\begin{tabular}{|l|c|c|}
\hline \multicolumn{1}{|c|}{ Município } & $\begin{array}{c}\text { Estad } \\
\text { O }\end{array}$ & $\begin{array}{c}\text { População } \\
\text { (Habitantes) }\end{array}$ \\
\hline São José dos Campos & SP & 681.036 \\
\hline Ribeirão Preto & SP & 658.059 \\
\hline Sorocaba & SP & 637.187 \\
\hline Joinville & SC & 575.480 \\
\hline Londrina & PR & 543.003 \\
\hline Campos dos & RJ & 480.648 \\
\hline Foytacazes & SC & 461.524 \\
\hline São José do Rio Preto & SP & 438.354 \\
\hline Santos & SP & 433.565 \\
\hline Mogi das Cruzes & SP & 419.839 \\
\hline Jundiaí & SP & 397.965 \\
\hline Maringá & PR & 391.698 \\
\hline Piracaba & SP & 388.412 \\
\hline Bauru & SP & 364.562 \\
\hline São Vicente & SP & 353.040 \\
\hline Franca & SP & 339.461 \\
\hline Cascavel & PR & 309.259 \\
\hline Guarujá & SP & 308.989 \\
\hline Taubaté & SP & 299.423 \\
\hline Petrópolis & RJ & 298.017 \\
\hline
\end{tabular}

\begin{tabular}{|c|c|}
\hline & 202.768 .50 \\
População Nacional & 2 \\
Participação deste Grupo & $4,04 \%$ \\
\hline
\end{tabular}

Austrália

\begin{tabular}{|c|c|c|}
\hline Município & Estado & $\begin{array}{c}\text { População } \\
\text { (Habitantes } \\
\text { ) }\end{array}$ \\
\hline Sunshine Coast & QLD & 285.169 \\
\hline Wollongong & NSW & 282.099 \\
\hline Geelong & VIC & 179.042 \\
\hline Townsville & QLD & 171.971 \\
\hline Cairns & QLD & 142.528 \\
\hline Toowoomba & QLD & 110.472 \\
\hline Ballarat & VIC & 95.021 \\
\hline Bendigo & VIC & 88.668 \\
\hline Albury-Wodonga & NSW/VIC & 84.982 \\
\hline Mackay & QLD & 81.594 \\
\hline Rockhampton & QLD & 77.704 \\
\hline Bundaberg & QLD & 69.805 \\
\hline Bunbury & WA & 67.090 \\
\hline Coffs Harbour & NSW & 66.610 \\
\hline Wagga Wagga & NSW & 53.832 \\
\hline Hervey Bay & QLD & 50.431 \\
\hline Mildura-Wentworth & $\begin{array}{c}\text { QLD/NS } \\
W\end{array}$ & 48.783 \\
\hline Shepparton-Mooroopna & VIC & 48.114 \\
\hline $\begin{array}{l}\text { Gladstone-Tannum } \\
\text { Sands }\end{array}$ & QLD & 44.355 \\
\hline Port Macquaire & NSW & 43.587 \\
\hline
\end{tabular}

23.605.100

$8,86 \%$

Fontes: IBGE (2010) e ABS (2012).

De acordo com os institutos nacionais de estatísticas, os 04 estados de cada país são alguns dos mais populosos de seus países e, a partir da análise da quantidade de cidades por estados percebe-se a tendência concentradora de população nos estados mais populosos. Enquanto São Paulo (estado brasileiro mais populoso) contribui com 13 cidades percebe-se que Queensland (segundo 


\section{Revista Nacional de}

Gerenciamento de Cidades

estado australiano mais populoso) apresenta 10 cidades: ou seja, os dois estados contribuem respectivamente com $65 \%$ e $50 \%$ em cada relação, expondo novamente o caráter concentrador da população nos estados mais populosos, simultaneamente demonstrar que a distribuição da população não ocorre de forma homogênea em cada território.

\section{CIDADES MÉDIAS: CENTRALIDADE E SISTEMAS DE TRANSPORTES}

Conforme algumas teorias presentes na Geografia Urbana acredita-se que as cidades médias representam um estágio de transição no crescimento das pequenas cidades, podendo este ser transitórias, quando estas continuam crescendo até atingir o tamanho de cidade grande. Sposito (2007) confirma este fato ao mencionar que ao passo em que o território possui algumas cidades que crescem (demograficamente e expansão da mancha urbana) mais do que as outras e confortam nódulos de articulação do território algumas destas cidades, futuramente alcançará a próxima categoria na hierarquia urbana (cidades grandes). Campinas, no interior do estado de São Paulo, cresceu ao longo do século XX e, ao final deste, já é percebida como uma metrópole.

De acordo com IBGE (2014), o município brasileiro de São José dos Campos (SP) é um exemplo desta afirmação: no censo brasileiro de 1940 a população do município era de 36.279 habitantes, alcançando 148.332 em 1970 (ou seja, apresentando-se como uma cidade média) e, já no ano 2000, residiam nestes municípios 539.313 pessoas. Apesar de apresentar razões específicas, observa-se que o crescimento vertiginoso deste município a períodos de 30 anos e, mantido este ritmo, no próximo período (2030), já estará incluso na categoria de metrópole. Como expressão australiana deste movimento observa-se Sunshine Coast (QLD), a qual apresentou taxa de crescimento vertiginoso no mesmo período de acordo com ASB (2014): entre os censos7 de 2006 e 2011 a população

\footnotetext{
${ }^{7}$ Enquanto IBGE realiza censos decenais, uma atualização no meio período e projeções anuais da população, ASB realiza censos quinquenais e estimativas anuais de aferição dos residentes no país.
} 


Revista Nacional de

Gerenciamento de Cidades
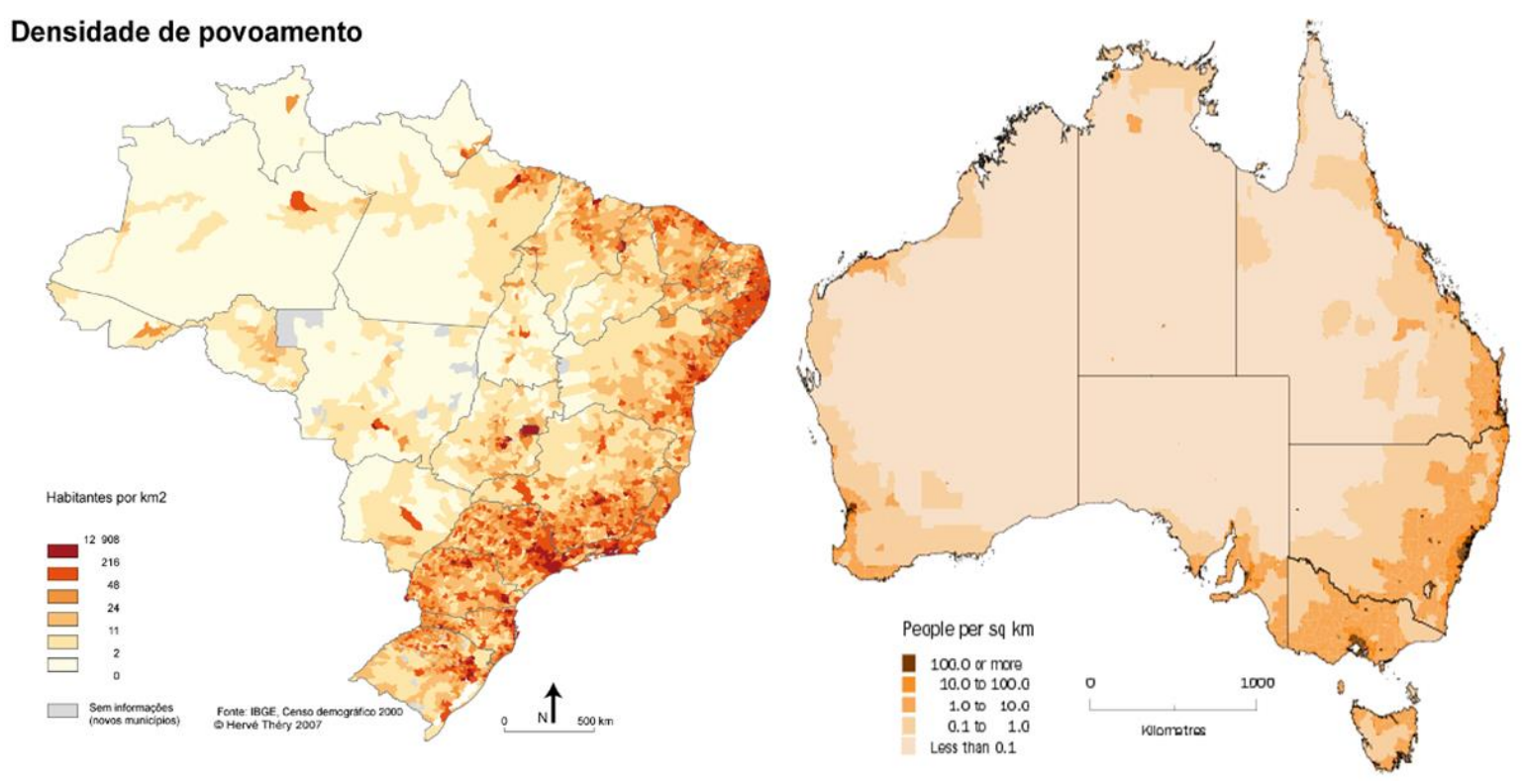

Fontes: IBGE (2010) e ABS

Retomando Corrêa (2007) e Santos (2007), o arranjo produtivo de um espaço está organizado por diversos fatores, sendo um dos principais a oferta de transportes para o deslocamento local e regional (primeiramente). Desta maneira, como melhor forma de administração dos recursos disponíveis em uma sociedade, os sistemas de transporte estão dispostos em redes nodulares, onde alguns pontos possuem acessos a outros de acordo com sua posição na hierarquia urbana. Ao considerarmos as maiores metrópoles o maior nível de oferta destes serviços, observam-se as cidades grandes logo a seguir, as cidades médias em nível intermediário e, na base desta organização, as cidades pequenas. Pode-se resumir esta afirmação ao expressar que as metrópoles são pontos de ligação entre todo o território nacional e também com o exterior, as cidades grandes comunicam-se com boa parte do território nacional e as cidades médias são os vínculos-chave entre as muitas pequenas cidades e as poucos grandes e metrópoles presente nos países.

Com isto, reforça-se que estes nódulos são pontos estratégicos de comunicação territorial em múltiplas escalas.Os Mapas 05 e 06 - Redes de Transporte Multimodal de Brasil e Austrália apresentam alguns dos pontos onde as redes encontram-se e distribuem-se ao longo dos respectivos territórios nacionais. 
Revista Nacional de

Gerenciamento de Cidades

\section{Mapas 05 e 06: Redes Multimodais de Transporte de Brasil e Austrália}
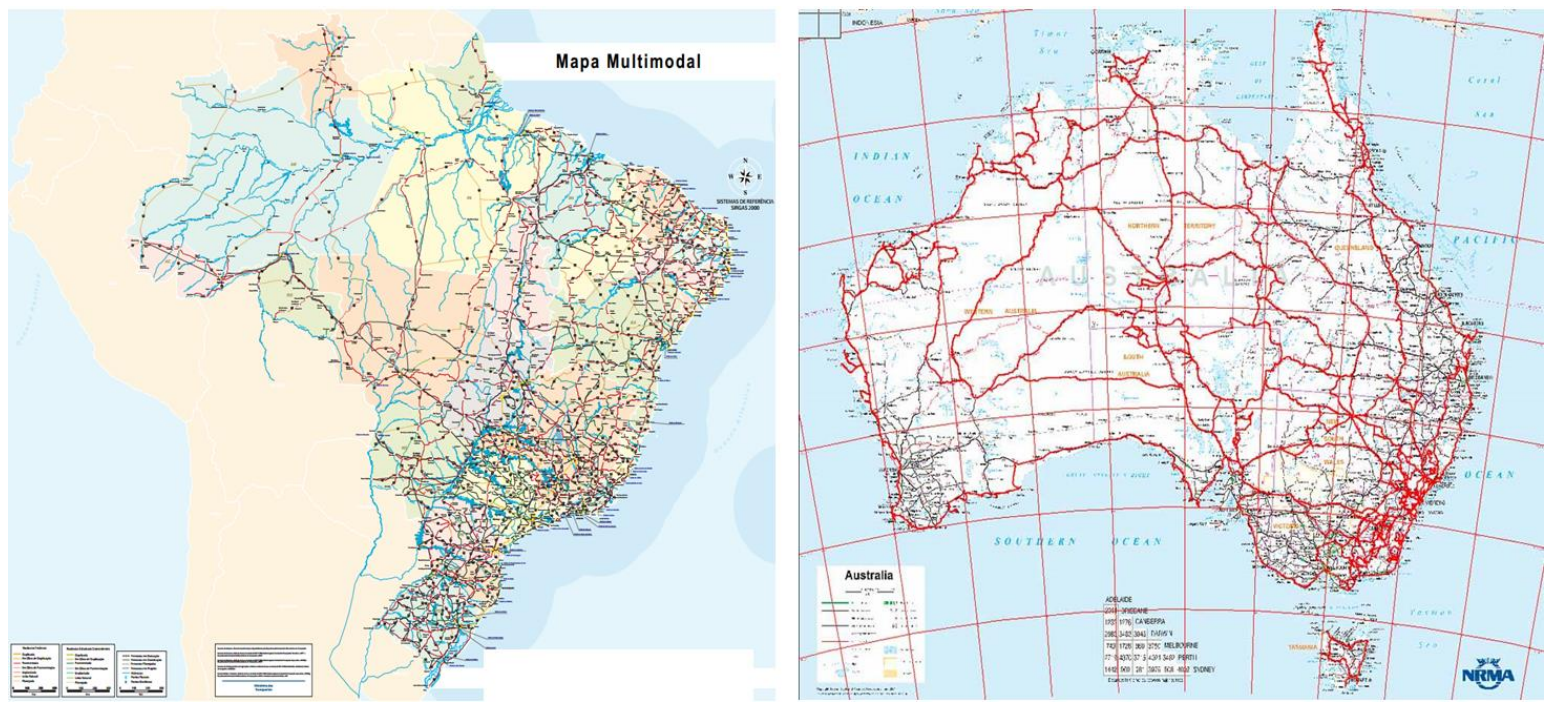

Fontes: ANTT (2013) e DIT

Os dois países analisados não são exceções a este fato. No território australiano, percebe-se a cidade de Bunbury, como um nódulo articulador entre os diversos pequenos municípios aos extremos Sul e Sudoeste do estado com outro polo regional de médio porte (Geraldton: 38.030 habitantes) e a capital Perth (1.627.576 habitantes). Além de oferecer serviços de ônibus e trens às duas maiores também articula serviços de pequena e média distância com todas as cidades locais as porções geográficas mencionadas. Desta maneira, Bunbury é um pólo de transportes ao receber e dissipar fluxos local e regionalmente. Sua equivalente brasileira é a Chapecó (SC: 210.009 residentes), localizada na porção centro-ocidental do território: servindo como um nódulo fundamental de conexão entre toda a porção oeste do estado (bem como partes do interior argentino e paraguaio) e as localidades mais centrais situadas ao Norte, Centro e Sul catarinense, como também das metrópoles nacionais Porto Alegre (RS) e Curitiba (PR). 


Revista Nacional de

Gerenciamento de Cidades

segunda maior metrópole australiana Melbourne (VIC) possui uma área total de $9.990,50 \mathrm{~km} 2$ sua equivalente brasileira, Rio de Janeiro (RJ) possui 7.062,35, ou seja, 30,03\% maior. Esta fenômeno impacta diretamente na distribuição dos modos e das frequências ao longo do espaço de cada cidade pois, enquanto na Austrália, existe uma tendência a busca de áreas cada vez mais longínquas e pouco densas para expansão urbana, no Brasil estas novas áreas de seguem padrão de densidade um pouco maior, enquanto as outras já tradicionais são constantemente sobreadensadas.

Ambos os países percebem suas cidades médias como as fronteiras transitórias do crescimento urbano nacional: de acordo com ABS (2012) e IBGE (2014), durante o primeiro decênio do século XXI, impulsionados pelo crescimento da economia chinesa e busca por produtos primários, ambas as economias nacionais mantiveram um ritmo de crescimento levemente superior à taxa global, mesmo no período de crise e recessão econômica internacional. Durante este mesmo período, apesar das metrópoles e grande cidades terem crescido, as maiores taxas foram apreciadas nas cidades médias, as quais cresceram consideravelmente mais do que aquelas presente na porção superior da hierarquia urbana.

Analisando estas afirmações segundo Santos (2007), este fenômeno significa não apenas a transição demográfica de um país para um momento de maturidade das metrópoles mas também do crescimento dos pequenos municípios. Ou seja, além de receber muitas novas empresas industriais e de serviços que estão deixando as cidades maiores, a demanda por novas atividades de maior complexidade nos vizinhos também impulsiona a expansão destas atividades nas cidades médias próximas. Desta maneira, a expansão acelerada dos pequenos municípios em conjunto o tímido crescimento metropolitano criaram um ambiente favorável a vantagem competitiva mencionada ao início por Kotler (2000): com o crescimento econômico ocorre a maior disponibilidade de recursos para planejamento, investimento e gestão dos sistemas de transportes local. Aliado a isto, os sistemas podem servir como vetores direcionais da expansão urbana, bem 
Revista Nacional de

Gerenciamento de Cidades

como limitador do ritmo de crescimento de cada localidade.

Percebe-se que boa parte das autoridades municipais dos estados aqui analisados estão investido em alternativas de transporte inovadoras para o contexto local, com o intuito de dotar com maior capacidade, presente e futura, os sistemas de transporte locais. Neste ponto, Bourne (1975) já alertava para a necessidade de integração de políticas para o desenvolvimento urbano australiano pois, ao passo que as políticas de habitação não estavam vinculadas diretamente a expansão multimodal de transportes os subúrbios cresceriam desordenadamente e gerariam demandas contínuas por outros serviços urbanos (como energia e saneamento, por exemplo). $\mathrm{O}$ autor indica ainda que uma política de adensamento balanceada dos subúrbios mais próximos as área centrais conjugada com boa oferta de transporte público são um caminho para o ordenamento do crescimento suburbano.

Neste mesmo ponto, Barat (2007) alerta que o excessivo adensamento de algumas áreas suburbanas brasileiras em contrapartida ao espraiamento e incorporação da franja periurbana ao tecido urbanizado das cidades gera desequilíbrios no aproveitamento de determinados serviços: enquanto algumas áreas sobreadensadas possuem demandas superestimadas para alguns serviços (como abastecimento de água e energia, por exemplo), outras sofrem com a falta dos mesmos. Novamente, o autor menciona que, para este caso, o adensamento brasileiro deveria ser balanceado e, mais ainda, em regiões de urbanização contígua, deveriam haver políticas populacionais distributivas entre os municípios buscando o equilíbrio de populações no espaço e melhor aproveitamento dos serviços urbanos.

Entretanto, ao invés de buscarem soluções locais para suas problemáticas, percebe-se a interpolação de modelos fechados das grandes cidades e metrópoles, não alcançando o resultado desejado além de criar novos problemas. Bannister (2010) afirma que os conceitos podem ser universais enquanto os mecanismos de implementação e as escolhas de alternativas são puramente locais, independente 0 grau de sucesso alcançado na cidade de origem.

Isto posto, a Rede Integrada de Transporte (RIT) da Grande Curitiba não 

Ferraz (2006) e Vasconcellos (2012) mencionam que as relações cotidianas demandam a criação natural de redes que visem atender as necessidades de toda a população. Por estas relações cotidianas os autores apresentam exemplos como deslocamentos de casa para o trabalho, demandas por equipamentos de saúde e ensino, lazer e entretenimento, visita a parentes e amigos, além da busca por produtos e serviços essenciais a sobrevivência individual.

Desta maneira, as demandas existentes para os sistemas de transportes são as mais diversas possíveis e o escopo de modos estruturais existentes deve conjugar sobretudo os principais elementos presentes na Relação Fundamental dos Transportes, segundo Vuchic (2005): capacidade, distância e velocidade.

Complementarmente, Chiavenato (2006) menciona que o aproveitamento máximo dos recursos disponíveis ocorre a partir de seu uso racional e contínuo, de maneira a não sobrecarregar uma estrutura em detrimento de outra. Bannister (2010), tal como muitos estudiosos de sistemas de transportes, acredita fielmente que a solução para o transporte público urbano está na transposição dos elementos presentes na Relação Fundamental de Transportes a um sistema que apresente a integração entre os diversos modos presentes. Ou seja, enquanto os modos de maior capacidade e velocidade são aplicados aos deslocamentos mais longos e com maior demanda, gradativamente, os modos de média e baixa capacidade são aplicados em distâncias menores e para demandas cada vez menores.

Como apresentado na secção anterior, as peculiaridades no processo de expansão urbana australiana e brasileira conjuntamente ao crescimento exponencial da frota de automóveis no primeiro decênio do século XXI apresentou um quadro preocupante na mobilidade urbana das cidades médias: com ritmo baixo de expansão das redes de transporte público, muitas vias antes descongestionadas passaram a apresentar volumes de tráfego superior a sua capacidade, aumentando o tempo de deslocamento e reduzindo a utilização adequada dos modos. Incluindo nesta situação o aumento da população residente nestes municípios e sua inerente busca por oferta de transporte (tanto público como privado), a situação atual está 


Revista Nacional de

Gerenciamento de Cidades

que apresentam aspectos peculiares em sua formação.

Badcock (2008) menciona que na Austrália o planejamento é um instrumento amplamente aplicado desde a conquista de autonomia perante o Reino Unido, ao início do século XX, apontando a criação da nova capital federal Canberra (1913) como maior expoente. No Brasil, Feldman (2005) igualmente afirma que o planejamento brasileiro também ocupa-se de gerenciar a ocupação do território e, da mesma maneira que seu colega australiano, menciona a construção da nova capital federal Brasília (1955) como grande estratégia. Entretanto, ambos também afirmam que apesar do planejamento e concepção inicial das cidades e sistemas nela inseridos, ao longo do tempo, as diretrizes não são devidamente seguidas e os problemas acumulam-se ao longo do tempo.

Os sistemas de transporte, como modeladores e delineadores de uso e ocupação do solo urbano também pode ser utilizados como instrumentos de controle e direcionamento da população local, tal como apresentado por diversos autores ao longo deste escrito e exemplificado em cidades de ambos os países. Harvey (1986) afirma que o controle da terra aliada ao provimento de infraestrutura urbana (em especial de transportes) é capaz de determinar os grupos que ocuparão as diversas áreas dentro de uma zona urbana.

As cidades de médio porte atualmente passam por um momento ímpar em suas histórias, onde o ingresso de novas empresas, habitantes e recursos financeiros, aliadas a observação de crescimento desordenado das grandes cidades e metrópoles no passado, permite a formulação de políticas e planos específicos para conter problemas futuros e permitir o uso balanceado de recursos financeiros, materiais e naturais presentes no território em busca de melhor qualidade de vida para toda população.

Ao mencionar os sistemas de transportes como elemento nevrálgico de planejamento urbano, Tsokalis (2009) menciona que a formação de redes é um elemento estruturador para o desenvolvimento de outras atividades do sistema urbano, pois de acordo com sua capacidade, serão observados diferentes níveis adensamentos, uso e ocupação do solo. Conjuntamente, Melhado (2013) aponto 


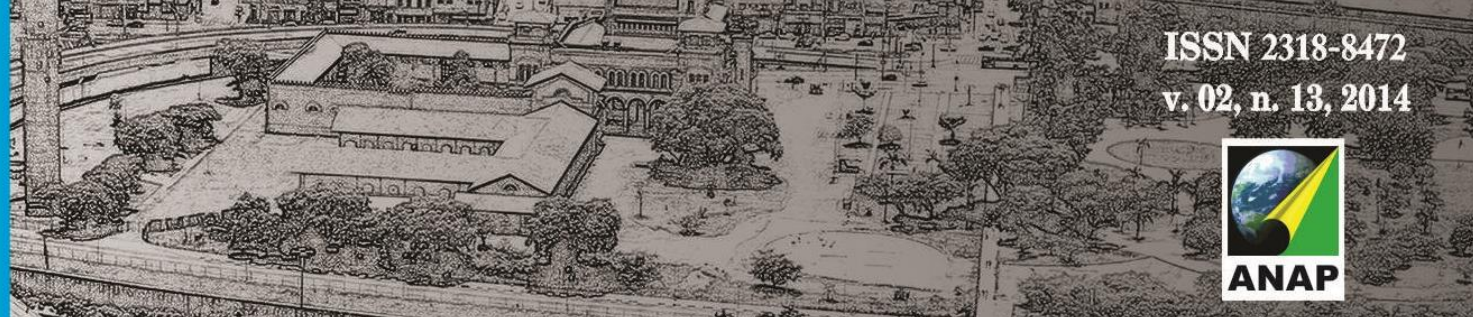

Revista Nacional de

Gerenciamento de Cidades

para o uso balanceado das estruturas existentes para o crescimento urbano sustentável e balanceado.

Muitas experiências estão sendo analisadas ou implantadas nos dois países e isto apenas reforça o papel do planejamento urbano no desenvolvimento e crescimento das cidades, tanto em épocas presentes como futuras. A partir deste é possível projetar cenários e formular soluções capazes de minimizar os impactos futuros do crescimento e, conjuntamente, buscar a distribuição mais justa de bônus a todos e não apenas do ônus que recaem, principalmente, sobre a população com menores níveis de renda.

\section{REFERÊNCIAS}

ABS. Australia National Census 2011. Canberra (Austrália): The Australian Bureau of Statistics Publishing, 2012.

AFG. Australia General Information. Canberra (Austrália): Australia Oficial Publishing, 2014.

ANTT. Anuário Brasileiro de Transportes. Brasília, Imprensa Nacional, 2013.

BADCOCK, Blair. The Urban Programme as an Instrument of Crisis Management in Australia. Londres (Reino Unido): Urban Policy and Research (Volume 11, Issue 02) (The Taylor and Francis Group), 2008.

BANNISTER, David. Integrated Transport: From Policy to Practice. Nova York (Estados Unidos): Routhledge Publishing, 2010.

BARAT, Josef. Logística, Transporte e Desenvolvimento Econômico. São Paulo: Editora CLA, 2007.

BOURNE, Larry Stuart. Urban Systems Strategies for Regulations: A Comparison of Policies in Britain, Sweeden, Australia and Canada. Londres (Reino Unido), The Oxford University Press, 1975.

BRYANT, Christopher (org). The City's Countryside: Land and it's management in the RuralUrban Fringe. Londres (Reino Unido), Longman Publishing, 1982.

DIAS, Patrícia (Org). Cidades Médias e Pequenas: Contradições, Mudanças e Permanências nos

Espaços Urbanos. Salvador: Editora SEI, 2012. 


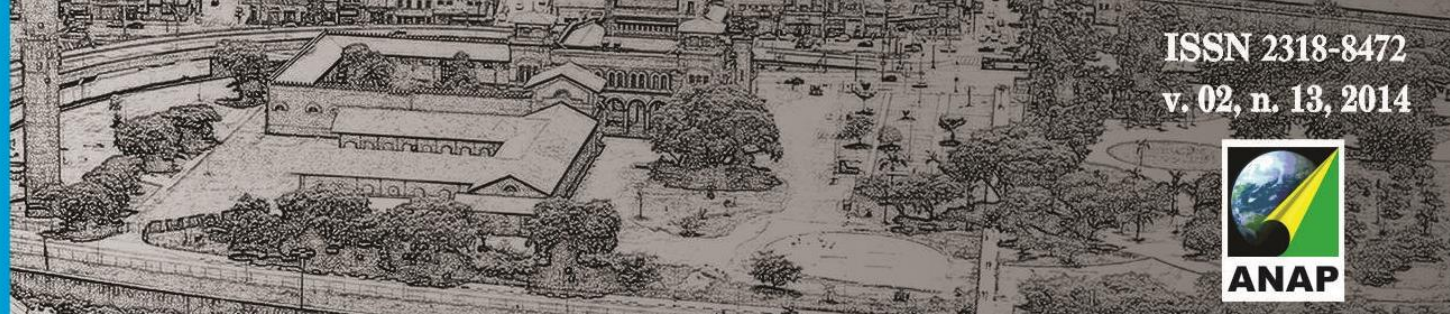

Revista Nacional de

Gerenciamento de Cidades

DIT. Australian Report About National Infrastructure Conditions. Canberra (Austrália): Australia Oficial Publishing, 2013.

CHIAVENATO, Idalberto. Administração Financeira: Uma Abordagem Introdutória. Rio de Janeiro: Elsevier, 2005.

CORREA, Roberto Lobato. Estudos Sobre a Rede Urbana. Rio de Janeiro: Bertrand Brasil, 2006.

CORREA, Roberto Lobato. Região e Organização Espacial. São Paulo: Editora Ática (8ª Edição), 2007.

FELDMAN, Sarah. Planejamento e Zoneamento: São Paulo de 1947 a 1972. São Paulo: EdUSP, 2005.

FERRAZ, Antônio Clóvis. Transporte Público Urbano. São Carlos: Editora Rima (2ª Edição), 2004.

FREESTONE, Robert. Cities, Citzens and Environmental Reform: History of Australian Town

Planning Associations. Sydney (Austrália): The Sydney University Press, 2009.

GOUVEA, Ronaldo. A Questão Metropolitano no Brasil. Rio de Janeiro: FGV Editora, 2005.

HARVEY, David. Do Gerenciamento ao Empresariamento Urbano: a Transformação da Administração Urbana ao Capitalismo Tardio. São Paulo: in Revista Espaço e Debate (Número 39), 1996.

IBGE. Censo Populacional de 2010. Brasília: Editora IBGE, 2010.

KOTLER, Philip (org.). Princípios de Marketing. Rio de Janeiro: Pearson, 2000.

MANKIW, Gregory. Introdução à Economia. Rio de Janeiro: Campus, 2000.

MELHADO, Ana (Org). Projetar e Construir Bairros Sustentáveis. São Paulo: Pini Editora, 2013.

MOSSO, Mário. Introdução a Estratégia de Qualidade. Rio de Janeiro: Editora ESC Cons, 2001.

ROLNIK, Raquel. O Que é Cidade. São Paulo: Editora Brasiliense (6를 Reimpressão), 2004.

SANTOS, Milton. Economia Espacial. São Paulo: EdUSP (2 $2^{\mathrm{a}}$ Edição / $1^{\underline{a}}$ Reimpressão), 2007

SANTOS, Milton. A Urbanização Brasileira. São Paulo: EdUSP (5 Edição / $2^{\mathrm{a}}$ Reimpressão), 2009.

SPOSITO, Maria Encarnação. Cidades Médias: Espaços em Transição. São Paulo: Editora Expressão Popular, 2007.

STILWELL, Frank. Economic Crisis: Cities and Regions. Rushcutters Bay (Austrália): Pergamon Press, 1982.

TAYLOR, Nigel. Urban Planning Theory Since 1945. Londres: Sage Publishing, 2007. 


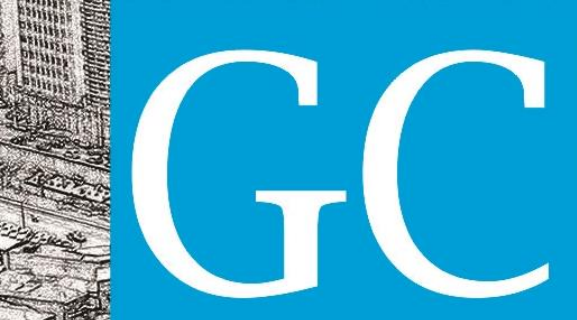

Revista Nacional de

Gerenciamento de Cidades

TSOKALIS, Dimitri (Org). Guide to Road Transportation Planning. Sydney (Austrália): Austroads Publishing, 2009.

VASCONCELLOS, Eduardo. Mobilidade e Cidadania. Rio de Janeiro: Editota SENAC, 2012.

VUCHIC, Vukan. Urban Transit: Operations, Planning and Economics. Hoboken (Estados Unidos), John Wiley and Sons Publishing, 2005.

VUCHIC, Vukan. Urban Transit: Systems and Technology. Hoboken (Estados Unidos), John Wiley and Sons Publishing, 2007. 